\title{
RUSSELL, MEINONG AND THE ORIGIN OF THE THEORY OF DESCRIPTIONS
}

\author{
HaRM BouKema \\ Philosophy / Radboud U. \\ 6500 HD Nijmegen, The Netherlands \\ HBOUKEMA@PHIL.RU.NL
}

According to his own account, Russell was "led to" the Theory of Descriptions by "the desire to avoid Meinong's unduly populous realm of being". This "official view" has been subjected to severe criticism. However stimulating this criticism may be, it is too extreme and therefore not critical enough. It fails to fully acknowledge both the way it is itself opposed to Russell and the way Russell and Meinong were opposed to their opponents. In order to avoid these failures, a more "dialectical" kind of analysis will be applied. It leads to unravelling two confusions shared by the official and the unofficial views: the confusion between conception and adoption of the theory of descriptions and the confusion between three varieties of Meinongianism. By means of these distinctions both a significant kernel of truth contained in Russell's account and the underlying motive for his distortion of the historical facts can be laid bare.

\section{O. INTRODUCTION}

\section{o.I The unofficial versus the official view}

$\mathrm{J}$

ust as natural numbers were not called natural until other, less natural ones were adopted, so the "official view" on Russell's famous Theory of Descriptions ("TOD") was not called official until fragments of another, unofficial one began to emerge. The most obvious and striking feature of the official view consists in its attributing a prominent role to Meinong as the philosopher who actually represented in its purest form the view the TOD is opposed to. Both the origin and the importance of Russell's theory are supposed to be out-and-out anti-Meinongian.

The official view on the TOD and its history is not just a piece of philosophical gossip whose prestige is mainly based on frequent and 
inconsiderate repetition; it has been strongly promoted by Russell himself. What is more, he seems to be its very originator. In "My Mental Development” Russell wrote: “... the desire to avoid Meinong's unduly populous realm of being led me to the theory of descriptions" (Schilpp, p. I3; Papers II: 13). This feature of the official view has greatly contributed to its long-lasting dominance. Who dares to doubt the reliability of the story told by the very person who might be supposed to have been better acquainted with the real background and genesis of the TOD than anyone else in the whole world?

Indeed, without the help of new, unsuspected evidence no one could have mustered the courage to challenge Russell's authority. The required support came from the manuscript "On Fundamentals" whose importance was discovered by Coffa 1980 . As appears unambiguously from this text, the TOD in fact was discovered on the occasion of a problem which has no obvious connection with Meinong at all, namely the one raised by the question how a denoting concept can be made the subject of a proposition.

In subsequent years new, although somewhat more controversial, evidence has been put forward against Russell's account, most notably by Griffin 1996, who has argued that the supposed Meinongianism or quasiMeinongianism that Russell wanted to get rid of by means of the TOD is merely fictitious. He concludes that

... contrary to what until recently was the almost unanimous view of philosophers, Russell's reasons for adopting his new theory of definite descriptions in 1905 could have nothing whatsoever to do with the need to prune back an unduly populous realm of being.

(Griffin 1996, p. 57)

Others, such as Cartwright 1987 and Hylton 1990, have adopted similar views. Although I do not know for sure how much support the unofficial view has found among Russell scholars, I assume its authority has sufficiently increased to provoke the question of how far its example is worth following.

\subsection{The need for further criticism}

There is one rather obvious reason for being suspicious of the belief that Russell's account is a mere myth. The importance of the fact, noted above, that the official story originated from its leading character has been overlooked. In virtue of this fact, the emergence of the official view 
is itself part of the true history of the TOD. In so far as Russell's own account deviates from what is supposed to be the true story, it asks for an explanation. What kind of motive might have enticed him to distort his own mental development?

The weakness of the newly established critical assessment of the official story consists not only in its failure to ask this question and to try to answer it, but also in its being so severe as to leave no room for any sound answer at all. If Russell's distortion of the historical facts is understandable, his account must at least contain some kernel of truth.

How could such truth be detected? Not by means of a reactionary attempt at gluing together the debris left by the iconoclasts in order to rehabilitate the official view. On the contrary, the elements of the official view are to be subjected to further deconstruction in order to detect the smaller pieces that may fit into a coherent whole. The extremism of the newly established critical analysis is not due to its being too critical or too analytical, but rather to its being not critical and analytical enough. For the ideal shared by all who are seriously engaged in criticism consists in the rejection of no less and no more than what on closer scrutiny appears to be false. Trying to avoid the rejection of what only seems to be false is just as essential and important as trying to avoid the acceptance of what only seems to be true.

\subsection{Preliminary analysis of the official view}

Analysis cannot proceed without some data which constitute its raw material. I'll therefore start by quoting more fully the above-mentioned passage from "My Mental Development".

Having described how in June I90I "the period of honeymoon delight" immediately after his visit to the International Congress of Philosophy in Paris ended by his discovery of the contradiction, Russell proceeds as follows:

At first, I hoped the matter was trivial and could be easily cleared up: but early hopes were succeeded by something very near to despair. Throughout 1903 and I904, I pursued will-o'-the-wisps and made no progress. At last, in the spring of 1905, a different problem, which proved soluble, gave the first glimmer of hope. The problem was that of descriptions, and its solution suggested a new technique.

Scholastic realism was a metaphysical theory, but every metaphysical theory has a technical counterpart. I had been a realist in the scholastic or Platonic sense; I had thought that cardinal integers, for instance, have a timeless being. 
When integers were reduced to classes of classes, this being was transferred to classes. Meinong, whose work interested me, applied the arguments of realism to descriptive phrases. Everyone agrees that "the golden mountain does not exist" is a true proposition. But it has, apparently, a subject, "the golden mountain", and if this subject did not designate some object, the proposition would seem to be meaningless. Meinong inferred that there is a golden mountain, which is golden and a mountain, but does not exist. He even thought that the existent golden mountain is existent, but does not exist. This did not satisfy me, and the desire to avoid Meinong's unduly populous realm of being led me to the theory of descriptions. What was of importance in this theory was the discovery that, in analysing a significant sentence, one must not assume that each separate word or phrase has significance on its own account. "The golden mountain" can be part of a significant sentence, but is not significant in isolation. It soon appeared that class-symbols could be treated like descriptions, i.e. as non-significant parts of significant sentences. This made it possible to see, in a general way, how a solution of the contradictions might be possible. The particular solution offered in Principia Mathematica had various defects, but at any rate it showed that the logician is not presented with a complete impasse.

(Schilpp, pp. I3-I4; Papers II: I2-I3)

The general tenor of this exposition is quite clear. Russell primarily wants to explain how he managed to cope with the paradox. In this connection the TOD comes in. Although that theory was not discovered on occasion of the paradox but on occasion of another problem, "the problem of descriptions", later on the new technique it provided proved to be of great importance in paving the way out of the impasse. So two different questions are answered in one stroke, namely "what was the decisive development leading to the solution of the contradiction?" and "what is the main logical importance of the TOD?"

What is the role of Meinong in this connection? Evidently, he is supposed to represent a canonical example of excessive realism. The TOD made it possible to circumvent ontological extravagance. What is more, it actually originated from "the desire to avoid Meinong's unduly populous realm of being". In saying so, Russell, of course, does not want to reveal an unsuspected feature of the TOD, but rather to add a little extra to the importance of a connection with which all readers who ever studied the TOD are supposed to be familiar. For it is a remarkable fact indeed that, although Russell's numerous expositions of the TOD differ significantly from each other in several respects, one element is to be found in all of them, namely a criticism of Meinong which is very nearly 
the same as the one expounded in this passage. ${ }^{\mathrm{I}}$ So, the essential point of Russell's notorious remark is that this criticism is of pivotal importance not only to the nature and the foundation or justification of the TOD, but to its genesis as well.

This distinction between genesis and justification may in a quite obvious way lead to another similar one, namely the distinction between the conception and the adoption of the TOD. It is, I think, quite significant that both Russell and the proponents of the unofficial view have failed to make the distinction. What Russell meant or at least suggested in saying that he was led to the TOD by his "desire to avoid Meinong's unduly populous realm of being" evidently is that, faced with "the problem of descriptions", a problem raised by his former theory of descriptions (the theory of denoting concepts put forward in The Principles of Mathematics, Chap. $v$ and connected with Meinong), he conceived and fully accept$e d$ his second theory of descriptions which afterwards appeared quite essential to the solution of the paradox.

The essential elements contained in this story seem to be as follows:

(aI) Meinong actually represented an extreme and excessive realism.

(a2) After his turn from idealism to full realism and before the discovery of the TOD, Russell had adopted at least some views very similar to those of Meinong.

(bI) These Meinongian or quasi-Meinongian elements were essentially connected with Russell's theory of denoting concepts.

(b2) On occasion of a difficulty in that theory, his desire to avoid his own Meinongianism arose.

(cI) This desire led to the conception of a new theory of denoting, the TOD.

(c2) Immediately after its conception, this new theory was fully and wholeheartedly accepted.

(c3) Afterwards the link with the paradox was discovered.

As far as I can see, these elements constitute the meaning of the official view. In order to separate their truth from their falsity I'll distinguish three varieties of Meinongianism. The first one, trans-realism, will be dis-

I See OD, Papers 4: 482-3; PM I: 66; "On the Nature of Truth and Falsehood", Philosophical Essays, p. I62 (Papers 6: II8); “The Philosophy of Logical Atomism”, LK, p. 248 (Papers 8: 196); Theory of Knowledge, Papers 7: 4Iff.; and IMP, p. I69. 
cussed in section I. Something like it is actually to be found in Principles. Section 2 will be concerned with the second variety: Meinong's essentialism. Neither it, nor anything like it, is compatible with Russell's realism. In section 3 I'll argue that the manifest connection with the theory of denoting concepts is merely accidental. Inspired by Frege, Russell made use of the theory in order to get rid of his own former quasiMeinongianism. In section 4 the third, essentially hidden variety of Meinongianism is taken into account. Russell's discovery of this cryptoMeinongianism, which took place after the TOD had been conceived but before it had been accepted, contributed to the adoption of the TOD, but was not sufficient to give rise to its full acceptance. The ideological character of the official story is not due to its claim that the TOD is out-andout anti-Meinongian, but rather to its suppressing both the retardation of the TOD's adoption and the problem which caused this retardation.

\section{QUASI-MEINONGIANISM IN THE CONTEXT OF RUSSELL'S REALISM}

\section{I.I Meinong's "excessive realism"}

Meinong would fiercely protest against being depicted as a proponent of a realism which is more excessive than its Russellian or Fregean variant. Typical of Meinong's theory of objects is not, as is suggested in the passage quoted in the previous section, an attempt to allow the intrusion of new and strange denizens into the realm of being, but rather to extend the range of possible thought and knowledge to objects beyond that realm.

In one important respect Meinong's realism is even less excessive than the one adhered to by Frege and Russell. For he refuses to attribute reality to false propositions, whereas according to Frege and Russell these are just as real as true ones. ${ }^{2}$

\footnotetext{
${ }^{2}$ The actual history of Russell's reception of this idea is rather complicated. In "On Meaning and Denotation" (1903, Papers 4: 319) Meinong's view is adopted in a somewhat modified form which evidently is inspired by Frege's idea that the distinction between sense and reference can be applied to sentences: a true proposition denotes a fact, a false one denotes nothing. In "Meinong's Theory of Complexes and Assumptions" (1904, Papers 4: 47I-4) this theory is rejected, and in OD it is adopted again (see Papers 4: 4902). It paves the way to the multiple relation theory of judgment conceived some years later. See "On the Nature and Truth of Falsehood" (I909, Papers 6: II8), where reference is made to Meinong.
} 
I do not want to suggest that Russell was completely unaware of these points. The latter is mentioned and extensively discussed in "Meinong's Theory of Complexes and Assumptions" (Papers 4: 47I-4). The first seems to be acknowledged in $O D$ where Russell much more fairly renders Meinong's view in saying:

Thus "the present King of France", "the round square", etc., are supposed to be genuine objects. It is admitted that such objects do not subsist, but nevertheless they are supposed to be objects.

(Papers 4: 418)

Still, the fact that 39 years later Russell spoke of "Meinong's unduly populous realm of being" instead of Meinong's unduly populous realm of objects, is not due to an insignificant slip of his pen. What he wants to convey is more complicated than he suggests, because it evidently bears not only on his opponent but on himself as well. Russell and Meinong both assume that any object of possible thought or knowledge is involved as subject matter, or as term as Russell calls it, in true and false propositions. Whatever may be thought of is such that some propositions about it are true and others are false. For if we suppose some object to be such that it stands alone, isolated from all propositions, then it would in virtue of that very circumstance be involved in the proposition that it is not involved in any proposition. ${ }^{3}$ Conversely, whatever occurs as term in some proposition could possibly be thought of. Russell and Meinong also share the conviction that beyond that realm of objects, i.e. beyond the realm of what may occur as object of thought and what actually occurs as term in propositions, there is absolutely nothing.

However, they disagree on the question how this all-embracing, transcendental realm is related to the realm of being. According to Russell, these realms are co-extensive; according to Meinong, they are not. Never - not when he wrote Principles, nor when he afterwards extensively studied the works of Meinong, nor, of course, after the adoption of the TOD-did Russell feel any inclination to accept objects without being.

Being is that which belongs to every conceivable term, to every possible object of thought - in short to everything that can possibly occur in any proposition, true or false, and to all such propositions themselves. Being belongs to whatever can be counted. If $A$ be any term that can be counted as one, it is plain that $A$

${ }^{3}$ Such a reflexive argument is typical of Russell’s realism. See $\$$ I.2 below. 
is something, and therefore that $A$ is. " $A$ is not" must always be either false or meaningless. For if $A$ were nothing, it could not be said not to be; " $A$ is not" implies that there is a term $A$ whose being is denied, and hence that $A$ is. Thus unless " $A$ is not" be an empty sound, it must be false - whatever $A$ may be, it certainly is.

(PoM, p. 449)

This view is at odds with the very starting point of Meinong's theory of objects, for that consists in the assumption that although it is always inconsistent to say of something that it is not something or not an object, it is far from inconsistent to say that something is not real and has no being.

However, Meinong never succeeded in convincing Russell of this view. In December 1904 Russell writes to him: "I have always believed until now that every object must in some sense have being, and I find it difficult to admit unreal objects" (Lackey 1973, p. I6).

We are now in a position to understand, at least partly, Russell's somewhat puzzling slip of the pen in "My Mental Development". ${ }^{4}$ As seen from the point of view of his persistent traditional and un-Meinongian conviction that the notion of being is transcendental and co-extensive with the notion of object or term of a proposition, Meinong's attempt to extend the realm of objects beyond being amounts to the same as an attempt to overcrowd the realm of being.

\section{I.2 Russell's realism}

Meinong's trans-realism, his attempt to stand up for both the epistemological importance and the unreality of unreal objects, is part of a larger philosophical project. He is dissatisfied with traditional metaphysics because in his opinion it does not succeed in fulfilling its own promise to be the most universal of all sciences. Meinong wants to free it from its established confinements in order to widen its scope. ${ }^{5}$

In this respect there is a very remarkable similarity with Russell's turn from traditional idealism to his revolutionary absolute and unrestricted realism. Due to the established inclination to overrate Moore's positive and Bradley's negative contribution to this revolution and to underrate Leibniz's part which is both positive and negative, this similarity has often been overlooked. However stimulating the new ideas of Moore

${ }^{4}$ For further discussion see $\$ \$ 2 . I$ and 4.3 .

${ }^{5}$ See Meinong 1904, p. 4. 
might have been to Russell, it is Leibniz, not Moore, who made him aware of the logical principle involved in all kinds of metaphysical idealism, not only in the particular one propounded by Leibniz, but also, to mention two important examples, in Bradley's holistic monism and in Russell's former pluralistic holism, namely that eventually every proposition must have a subject and a predicate:

In the belief that propositions must, in the last analysis, have a subject and a predicate, Leibniz does not differ either from his predecessors or from his successors. Any philosophy which uses either substance or the Absolute will be found, on inspection, to depend upon this belief. Kant's belief in an unknowable thing-in-itself was largely due to the same theory. It cannot be denied, therefore, that the doctrine is important. Philosophers have differed, not so much in respect of belief in its truth, as in respect of their consistency in carrying it out. In this latter respect, Leibniz deserves credit.

$(P L$, p. I5)

What does the "belief that propositions must, in the last analysis, have a subject and a predicate" have to do with idealism? And why does its rejection lead to realism? Here we meet the second obstacle that might prevent us from understanding the nature of Russell's realism. These questions cannot be answered as long as the classical Aristotelian and Kantian view of logic as a kind of formal proto-science which precedes real knowledge and does not involve any metaphysical assumptions, is taken for granted. But there are good reasons not to do so, for Russell never subscribed to such a view, neither during ${ }^{6}$ nor after his idealist period. Therefore, the subject-predicate principle is to be construed as logico-metaphysical in character. There is one, and as far as I can see only one, way to meet this requirement: by taking into account the notion of substance.

The idealist principle that Leibniz made Russell aware of bears on the connection between truth and being. Whatever is true is eventually, "in the last analysis", 7 true about what is supposed to be the only really real

${ }^{6}$ See An Essay on the Foundations of Geometry, \$56, pp. 64-6.

7 Such an analysis is based on the Aristotelian principle that the more universal only exists in its less universal specifications. A "generic" universal such as "coloured" is supposed to have no other being than being embodied in specific ways of being coloured, such as being red. This principle is denied by Russell. See PoM, p. I38: "Redness, in fact, appears to be (when taken to mean one particular shade) a simple concept, which, although it implies colour, does not contain colour as a constituent." 
kind of thing, namely a concrete existent, a substance. Single substances are, in virtue of their being "in themselves" and not in something else, the ultimate subjects of propositions. And what is true about them consists in their being qualified, in their having predicates which are supposed to be their private properties. These predicates or "accidents" are not in themselves. The only way they are is to be in the substance they belong to. Their esse is in-esse.

In my opinion, the idealism that Russell is opposed to is not primarily epistemological in character, as Hylton 2004 has suggested (pp. 207-I2), but is metaphysical. It involves the exclusion of all kinds of things from the realm of real being. Whatever cannot be construed as a concrete individual or as one of its private properties must be unreal, or at least not fully real. It is relegated to the realm of the merely ideal, i.e. the realm of abstract conceptual deviations from reality which may point to it because they are derived from it, but do not properly belong to it.

What kinds of items are deemed to dwell in this limbo? Universals, relations, propositions (especially false ones), space, time, infinity and last but not least: plurality. And these, of course, are exactly the things the realist Russell is anxious to allow unrestricted entrance into the realm of being. Just as idealism is based on restricted aboutness of propositions, so the main philosophical principle underlying the logic of Principles claims their unrestricted aboutness.

However, Russell's realism is not unlimited without qualification. It does not at random attribute being to whatever might supposed to be real, but, at least as far as logic is concerned, only to those items that must be acknowledged because they are presupposed in the very assumption that they are not. For example, there must be truth, for if there were no truth, it would be true that there is no truth. Also: there must be many truths, for if there were only one truth, then that very truth would be the only one there is, which is absurd. For the sake of brevity, I'll call this feature of Russell's realism reflexive determinism.

\section{I.3 Russell's quasi-Meinongianism}

We are now in a position to allow due weight to the context in which the most notable piece of evidence in favour of Russell's supposed "Meinongianism" occurs, namely the passage from Principles subsequent to the one quoted in \$I.I. Here Russell says: 
Numbers, the Homeric gods, relations, chimeras and four-dimensional spaces all have being, for if they were not entities of a kind, we could make no propositions about them. Thus being is a general attribute of everything, and to mention anything is to show that it is.

Existence, on the contrary, is the prerogative of some only amongst beings. To exist is to have a specific relation to existence-a relation, by the way, which existence itself does not have. This shows, incidentally, the weakness of the existential theory of judgment - the theory, that is, that every proposition is concerned with something that exists. For if this theory were true, it would still be true that existence itself is an entity, and it must be admitted that existence does not exist. Thus the consideration of existence itself leads to non-existential propositions, and so contradicts the theory. The theory seems, in fact, to have arisen from neglect of the distinction between existence and being. Yet this distinction is essential, if we are ever to deny the existence of anything. For what does not exist must be something, or it would be meaningless to deny its existence; and hence we need the concept of being, as that which belongs even to the non-existent.

(PoM, pp. 449-50)

The larger context of this passage will be discussed in \$2.3. For the present purpose it is sufficient to note that Russell is arguing against one of the main points implied by the idealist principle mentioned in the previous section, the restriction of the aboutness of propositions to existents or, what amounts to the same, to substances and their accidents. ${ }^{8}$ In order to prove that this restriction is intolerable, Russell makes use of his favourite reflexive mode of argument: if it were true that whatever is true is true of some existent, then it would be true as well that existence belongs to all entities. That very supposed truth, however, would itself be an example of a proposition concerning a non-existent universal.

Therefore, being is wider than existence. Although a sentence of the form " $A$ is not" can never express a true proposition, a sentence of the form " $A$ does not exist" may quite well do so, for example "Existence does not exist". And, of course, it is quite easy to give similar examples

${ }^{8}$ Russell takes the notion of existence, borrowed from traditional metaphysics, as widely as possible. If something is really in space and time or only in time, it exists. If space and time and the points or moments they consist of, are real, they exist as well. See PoM, p. 449: "Both being and existence, I believe, belong to empty space." Finally, if God really is, then God exists in spite of His being beyond time. See "The Existential Import of Propositions" (Papers 4: 486), where the "super-sensible existence attributed to the Deity" is mentioned in this connection. 
that Russell might have had in mind, such as: "the relation 'greater than' does not exist" or "the number 2 does not exist".

As far as these and similar examples are concerned, Russell's contention is quite innocent. Both Meinong and Frege would agree with him. But no doubt Russell also wants his view to be applied to examples of a different kind, such as "Zeus does not exist" or "Pegasus does not exist". At least, that seems to be implied by the first part of the text quoted above. For according to Russell Homeric gods are entities because, and in so far as, they can be mentioned. And mentioning a Homeric god, of course, does not consist in the use of the phrase "Homeric god" or of some denoting phrase derived from it, but in the use of one of the divine proper names that actually occur in Homer's Iliad or Odyssey.

\section{QUASI-MEINONGIANISM WITHOUT ESSENTIALISM}

\section{I The possibility of quasi-Meinongianism without essentialism}

Russell and Meinong both accept that "Zeus" is a genuine proper name standing for a non-existent object. They agree on the truth of the proposition that Zeus does not exist. What other propositions about Zeus are supposed to be true? Take, for example, the proposition that according to Greek mythology Zeus, assuming the form of a white bull, carried off a pretty nymph called Europa. Both Russell and Meinong, I presume, would accept its truth without further ado.

But what about the supposed fact that Zeus abducted the said nymph? Is it a real fact? According to Meinong it is! Why so? Why not assume that the supposed facts concerning Zeus are just as unreal as Zeus himself? Such a view seems much more appropriate to a philosopher who wants to speak in defence of the unreal.

The importance of this rather obvious question has been overlooked by both the adherents of the official view and their opponents. Ayer and

${ }^{9}$ I concede that in the case of chimaeras this interpretation is less plausible, because, as far as I know, they lack proper names. I do not think, however, that this difficulty is serious enough to prove that Russell never could have held the view I attribute to him. In fact, he is not primarily concerned with language at all. His main argument is rather that if a definite chimaera occurs in a certain story, then denying the existence of that particular chimaera would be impossible unless the story is really about some entity. And every particular entity which actually is presented to the mind can be mentioned by means of a proper name. 
Quine assume as a matter of course that it is impossible to allow fictional characters or Homeric gods to be genuine objects without giving credit to all established stories that purport to be about them. Applied to the Russell of Principles this amounts to the same as assuming that if he concedes that Homeric gods and chimaeras are entities — and, as appears from the text quoted in the previous section, there is overwhelming evidence in favour of that assumption - then he must suppose propositional functions such as " $x$ is a god dwelling at the top of the Olympus" or " $x$ is a chimaera" to be true for some values of $x$.

However, as Griffin 1996 has pointed out (p. 49), these adherents of the official view just ignore that according to Principles, $\$ 73$, page 74 , "chimaera" is a null-class concept, i.e. the propositional function " $x$ is a chimaera" is false for all entities. Taking this textual evidence as his point of departure, Griffin argues in the opposite direction, concluding that Russell's supposed quasi-Meinongianism must be a myth. Indeed, as Griffin is prepared to admit, this challenging conclusion asks for a new interpretation of Russell's saying that chimaeras are entities. And he actually provides an ingenious one (p. 54), namely that Russell failed to use inverted commas. What he actually meant is not that chimaeras are entities, but rather that denoting concepts derived from the class concept "chimaera", such as "all chimaeras" or "some chimaeras", are entities.

It is quite implausible that Russell failed to use the very italics or inverted commas which according to the Principles, $\$ 56$, page 53, are of utmost logical importance. Furthermore, neither in $\$ 427$ where chimaeras are actually said to be entities, nor in any other part of the chapter to which that section belongs, are denoting concepts at issue. Finally, if Griffin's exegesis were right, Russell could just as well have mentioned things like even prime numbers greater than 2. Ignoring the fact that he did not do so amounts to ignoring the main point of the text, namely that being is not confined to existence.

As soon as the assumption shared by Griffin and his opponents is abandoned, another much less far-fetched solution appears to be possible. The inverted commas Russell could have used are rather scare quotes. What is more, it is quite understandable that he did not use them, for according to the dictionary a chimaera is something that according to ancient Greek stories is a creature with a lion's head, a goat's body and a snake's tail that can exhale fire. And as far as Homeric gods are concerned, there is no need of scare quotes at all, because Homer occurs in their definition. Of course, in saying that "chimaera" is a null-class 
concept, Russell did not mean that there are no entities which according to ancient Greek stories are such and such, but rather that there are no entities which are such as ancient Greek mythology supposes them to be. After all, why would Russell's firm belief in the aboutness of Greek mythology force him to believe in Greek mythology itself ?

\subsection{Russell's realism versus Meinong's essentialism}

Against this interpretation a serious objection could be raised, namely that it imputes a very strange and abstract, not to say inconsistent, belief in characterless characters to Russell. This difficulty may help us to get down to the very heart of the matter. For if the Russell of Principles actually held the view I attribute to him, Meinong would strongly disagree. Why? That, in fact, is the very same question as the one asked in the previous section. So let us now try to answer it.

Meinong would blame Russell for crypto-psychologism. For the assumption that, apart from the fact that Zeus does not exist, all real facts concerning him involve human imagination and belief, seems to be very near psychologism. It implies that the nature (Sosein) of the object called Zeus would be wholly determined by the mental acts performed by the Greeks. In short, as seen from Meinong's perspective, the view I attribute to Russell is an inconsistent and half-hearted mixture of objectivism and subjectivism. On the one hand Zeus would be some particular object whose identity is fixed independently of human thought. On the other hand his being such-and-such would merely consist in his actually being supposed to be so-and-so by certain people.

Most philosophers are prone to thinking that whatever is unreal is either in the mind or somehow created by it. According to Meinong this view is inconsistent. For whatever is in the mind must be a real part of a real mental process. And whatever is produced by the mind must be real as well. Creation cannot be real unless it results in something real. Although unreal objects are outside being, they must in some way or other be in touch with being. Unreal objects need to be propped up by real facts concerning them in order to be objects at all. But these facts cannot all of them be mental. The only facts that may provide the needed support are Soseinsobjektive, i.e. facts constituting their essence, their being what they are. Zeus, for example, derives his identity from the fact that he is male, not female, super-human, not just one among mortals, master of thunder and lightning, not of love or fertility.

Meinong's essentialism is based on the idea that objects need to have 
intrinsic properties in order to be distinct objects at all. Because distinctness or difference is a relation, this assumption may be viewed as a particular application of the general principle that "every relation is grounded in the nature of the related terms". It goes without saying that this axiom of internal relations, as Russell called it, is incompatible with the very essence of his realism. ${ }^{\text {IO }}$

\subsection{The context of Principles, $\$_{4} 27$}

It is a remarkable and revealing fact that the notorious $\$ 427$ in which chimaeras and Homeric gods are ranked among entities is part of a chapter on "Logical Arguments against Points". This chapter is almost entirely devoted to a criticism of Lotze, who takes a stand close to Leibniz and also close to the idealist Russell, although the latter is not mentioned by the Russell of Principles. ${ }^{\text {II }}$

One of the canonical idealist arguments against the possible reality of empty space is that apart from the different things that occupy space, all points are exactly alike. They seem to be different, but their difference consists in nothing at all. Points are colourless and without character. Or, as the idealist Russell used to say, there is a conception of diversity without diversity of conception. The realist Russell's retort is:

To be exactly alike can only mean - as in Leibniz's Identity of Indiscernibles - not to have different predicates. But when once it is recognized that there is no essential distinction between subjects and predicates, it is seen that any two simple terms differ immediately - they are two, and this is the sumtotal of their differences.

(PoM, p. 45I)

In saying that "there is no essential distinction between subjects and predicates" Russell means that any predicate, and more generally any constituent of a proposition, may occur as genuine subject. For according to him the in-esse which marks the traditional absolute distinction between substances and their accidents is to be rejected.

This argument may also be applied to Homeric gods. Apart from all the stories told about them, they are indeed exactly alike. But that does

Io See "The Classification of Relations" (Papers 2: I43) and MPD, Chap. 5, where sec. II of "The Monistic Theory of Truth", originally "a paper read to the Aristotelian Society in 1906, which deals with Harold Joachim's book on The Nature of Truth", is extensively quoted. See Philosophical Essays, pp. 139-46.

${ }^{\text {II }}$ See Foundations of Geometry, \$\$194-6, pp. 185-7. 
not prevent them from differing immediately from each other. Therefore, the very same argument that seemed to be a serious objection to my interpretation, namely that it forces upon Russell the strange and unacceptable view that fictional characters are in themselves colourless entities, in fact forces upon him a view much too commonsensical and Aristotelian to be compatible with the radical externalist stand of his logic. Maybe this externalism is to be rejected, but if so, not in virtue of its being at odds with common sense but in virtue of its possible inconsistency. And if it is to be rejected, that cannot be a sound reason for denying that Russell ever adhered to it.

\section{THE ACCIDENTAL LINK WITH THE THEORY OF DENOTING CONCEPTS}

\section{I Russell's quasi-Meinongianism as accidental and independent of the} theory of denoting

Thus far I have argued for the actual existence of Russell's quasi-Meinongianism. I have done so in making use of a rather uncommon view of the nature of Russell's realism, or rather of the way it is opposed to his former idealism. In this connection two aspects of his realism appear to have played a prominent role. Its Platonic trans-existential import prompted Russell to quasi-Meinongian extravagance, and its externalist slant restricted it in such a way as to make it compatible with the quite unMeinongian concession that Homeric gods and chimaeras do not, and need not, have the properties ascribed to them by Greek mythology.

But, however important these two features of Russell's realism may be for the nature and limitations of his quasi-Meinongianism, they neither forced him to adopt it, nor prevented him from actually doing so. This indeed, is quite essential to the view I argue for. Russell's manifest quasiMeinongianism, although surrounded by fundamental ideas, is itself not fundamental at all. It does not reveal any manifest deep-rooted ontological extravagance, but rather a quite superficial and momentary extravagance in giving examples of non-existent entities. Russell's argument against Lotze would be just as good as it is, if he had not allowed Homeric gods and chimaeras entrance into the realm of being.

The theory of denoting concepts is not able to add anything to the limited importance of Russell's quasi-Meinongianism. For although that theory presupposes that there are Russellian proper names, it itself is not concerned with them. Once the view is adopted that "Zeus" is a genuine 
proper name, the distinction between meaning and denotation cannot be applied to it. That, indeed, is one of the most conspicuous and notorious differences with Frege's theory of sense and reference.

\subsection{The theory of denoting concepts as first aid}

Although the theory of denoting is unable to support the existence of Russell's quasi-Meinongian extravagance, or its non-existence, or its emergence, or even the desire to avoid it, nevertheless, for some reason or other, once its emergence has actually taken place and, for some other reason, once the desire to effect its disappearance is awakened, the said theory could possibly be of great help. What is more, it seems to be the only available theory able to assist. For if Russell wants to banish Zeus and his congeners from the realm of being, he will have to give up his former belief that "Zeus" and similar expressions are genuine proper names. And in that case there are only two possible options. Either such an expression is supposed to have no logically relevant signification at all, or it is supposed to be a denoting phrase in disguise, which expresses a complex meaning (made up of all the properties which according to Meinong are essential to Zeus), but does not denote anything. It goes without saying that the latter alternative is to be preferred.

As far as I know, the manuscript "On Meaning and Denotation", written in the second half of 1903 , is the earliest text that testifies to the actual existence of such a move:

Such phrases as "Arthur Balfour", "two", "yellow", "whiteness", "good”, "diversity", and single words generally, designate without expressing: in these cases, there is only a single object for the phrase, namely the object which it designates. But when a phrase contains several words, not simply juxtaposed, but in any way combined so as to acquire unity, then the phrase, as a rule, expresses a complex meaning. In such a case, there may be no object designated: for example, "the present King of France" expresses a meaning, but does not designate an object. The same holds of "the even prime other than 2", "the rational square root of 2", "the bed in which Charles I died", or "the difference between Mr. Arthur Balfour and the present Prime Minister of England". In all such cases, the meaning expressed is perfectly intelligible, but nothing whatever is designated. In the case of imaginary persons or places, such as Odysseus or Utopia, the same is true. These appear to be proper names, but as a matter of fact they are not so. "Odysseus" may be taken to mean "the hero of the Odyssey", where the meaning of this phrase is involved, and not the imagined object designated. If the Odyssey were history, and not fiction, it would be the designation that would be in question: "Odysseus" would then not express a meaning, but would 
designate a person, and "the hero of the Odyssey" would not be identical in meaning with Odysseus, but would be identical in designation. And so in the other cases, "the present King of England", "the even prime", "the positive square root of 2", "the bed in which Cromwell died", "the difference between Mr. Chamberlain and the present Prime Minister of England", are all phrases which have both meaning and designation.

(Papers 4: 318)

What might have caused Russell's desire to get rid of his own quasiMeinongianism? If, as I have argued in \$3.I, it is not much more than an insignificant lapse, then the desire to correct it need not be very fundamental either. It seems to be occasioned by Russell's study of the works of Frege and Meinong. The example of Odysseus seems to be borrowed from Frege's "Über Sinn und Bedeutung". ${ }^{\text {I2 }}$

Furthermore, from the first part of the text quoted above, it might be inferred that according to Russell all proper names of abstract entities are single words or derived from them as "whiteness" is derived from "white" or "difference" from "different". If this conjecture is right, expressions such as "Odysseus" or "Zeus" cannot be construed as proper names of non-existent entities. And because they are not, of course, proper names of existent entities either, they cannot be proper names at all.

\subsection{The insufficiency of the quasi-Fregean solution}

Is the aid lent by the quasi-Fregean variant of the theory of denoting concepts sufficient to satisfy Russell's desire to get rid of his former quasiMeinongianism? In order to answer this question, it may be helpful to split up Russell into three personalities: the quasi-Meinongian, the unsatisfied, and the quasi-Fregean one.

The quasi-Meinongian Russell does not labour under any constraint. True, he supposes himself to be forced to accept Zeus's being, but he does so in order to be free to deny Zeus's existence. The distinction between being and existence is his main concern. Failing to acknowledge this distinction, his opponent Lotze is forced either to accept Zeus's existence or to deny that the sentence "Zeus does not exist" expresses a genuine, true or false, proposition at all.

As seen from the point of view of the unsatisfied Russell, being forced to accept Zeus's being actually is a constraint. He wants to get rid both of Zeus's being and the supposed necessity that forced him to accept it.

${ }^{12}$ Frege 1892, pp. 148-9. 
In fact, he wants to get more freedom than the freedom to deny existence, namely the freedom to deny being as well. And that, after all, might be a very deep desire concealed under the surface of the rather superficial ones discussed in the previous section. ${ }^{\mathrm{I}}$

Is the quasi-Fregean Russell able to fulfil this deeper need? According to Peter Hylton he is:

If we have a sentence containing the name or the definite description " $A$ " then, as before, if the sentence is meaningful it must express a proposition. Given the theory of denoting concepts, however, this proposition need not contain the object $A$ itself; it may, rather, contain a denoting concept which denotes $A$ (or purports to do so). There being a proposition of that kind, however, does not require that there actually be such an object as $A$ (or at least the requirement is by no means obvious).

It now becomes possible for the sentence " $A$ is not" to be both meaningful and true-i.e., to be meaningful even though there is no such thing as $A$. The difference is that now $A$ need not be counted among the constituents of the proposition; instead of containing an object $(A)$, the proposition is now said to contain a denoting concept which, as it happens, does not denote anything.

(Hylton 2004, pp. 216-17)

Hylton, I presume, is prepared to admit that a sentence such as "Zeus abducted Europa" will express a proposition which is neither true nor false, as soon as "Zeus" is construed as a denoting phrase in disguise. So, in general, the quasi-Fregean solution will result in truth-value gaps. But, at least as I understand Hylton, there is one exception: the sentence "Zeus is not" will express a true proposition, because its not being about anything at all seems to provide the very reason for its being true!

To me, this interpretation is too paradoxical, and I can hardly believe that Russell would have accepted it. Hylton deserves credit for having discussed the crucial question which indeed must be answered affirmatively if the unofficial view is to be rescued in another way than the one proposed by Griffin. And if the first aim I have set myself (see \$o.2) is attainable - if it is possible to lay bare a substantial kernel of truth contained in the official view - then Hylton's solution is to be rejected.

What might lend credibility to his view is the fact that the proposition expressed by "the god of thunder and lightning dwelling at the top of

${ }^{13} \mathrm{My}$ use of the opposition between freedom and constraint is borrowed from Quine I948. 
Mt. Olympus is not" seems to be equivalent to the proposition that "the god of thunder and lightning dwelling at the top of Mt. Olympus" [i.e. the denoting concept] has no denotation. This solution, although never put forward by Frege, would be quite Fregean in spirit. For it is based on the un-Meinongian principle, used long before the introduction of the distinction between sense and reference, that the problem of non-being is to be avoided in translating non-being into non-having and changing the subject matter accordingly. ${ }^{14}$ Evidently the viability of such an eliminative paraphrase is based on the un-Russellian assumption that equivalent sentences always express one and the same proposition. ${ }^{\text {I5 }}$ Finally, this approach is based on Frege's belief that any sense may occur as subject of a proposition by means of the indirect sense, which is supposed to be in some way derived from the direct sense, as is indicated by the inverted commas.

\section{CONCEPTION AND DELAYED ADOPTION OF THE TOD}

\section{I Trans-Fregean discoveries}

As appears from Principles, $\$ 476$, page 502, Russell initially rejected Frege's notion of indirect sense. He did so, not because it involves an infinite regress, but because he supposed it to be superfluous. For he rather inconsiderately assumed that a denoting concept may occur as term of a proposition more or less in the same way as other concepts may. "If we wish to speak of the [denoting] concept, we have to indicate the fact by italics or inverted commas" (PoM, \$56, p. 53). Inverted commas are deemed to merely indicate a change in occurrence.

From 1903 onwards Russell begins to realize that the peculiar way denoting concepts primarily occur, namely in a subject-position without being the subject of a proposition, prevents them from being made the subject of a proposition in the same way as a predicate or a relation. ${ }^{16}$ So he comes to see the need of something like Frege's indirect sense. In order to become the subject of a proposition, a complex denoting concept $C$ has to occur in another, larger denoting concept " $C$ " which de-

${ }^{\mathrm{I} 4}$ Frege I884, $\$ 46$, p. 59.

I5 See for Frege's view: Frege 1879, pp. 2-3, and for its denial, although without any reference to Frege: PoM, pp. 228-9.

${ }^{16}$ See "On Meaning and Denotation" (Papers 4: 320-I) and "On Fundamentals" (Papers 4: 363). 
notes $C$. The inverted commas are now supposed to indicate an addition.

It is quite essential in this connection that, although the larger denoting concept " $C$ " always has to be definitely denoting, the denoting concept $C$ which is supposed to be denoted by " $C$ " may just as well be ambiguously denoting. In the manuscript "On Fundamentals", Russell more or less accidentally hits on the question of how the supposed additional inverted commas are to be explained (Papers 4: 38I). In making an attempt to answer this question, he discovers that they cannot be explained at all, because all denoting concepts, whether they do or do not occur in another denoting concept, occur in an entity position anyhow, i.e. as denoting.

In discussing the nature of this unsuspected problem, Russell makes an unmarked change from ambiguously denoting concepts such as "any man" (his very first example) to definitely denoting concepts such as "the centre of mass of the Solar System" (Papers 4: 383). Then he makes a second discovery. In the case of unambiguously denoting concepts, the problem concerning the explanation of the inverted commas can be avoided by means of a (quasi-Fregean) eliminative paraphrase. For the proposition that "the $S$ " denotes something, is equivalent to and therefore, at least according Frege's assumption, identical with the proposition that the class-concept $S$ or the propositional function " $x$ is an $S$ " has one and only one instance. And that may be expressed by means of quantifiers in the way indicated by Frege himself. ${ }^{17}$ Applying this procedure to sentences of the form "the $S$ is $P$ " leads to the TOD. This, then, is the way the new theory is conceived.

In the very same section, Russell also discovers another possible advantage of the TOD, namely that it may explain the informative character of identity statements in a much better way than the old theory of denoting concepts did. However, a few pages later the brand-new theory is rejected:

The most convenient view might seem to be to take everything and anything as primitive ideas, putting

$$
\begin{aligned}
& (x) \cdot \phi^{\prime} x=. \phi^{\prime} x \text { (everything) } \\
& (x) \cdot \phi^{\prime} x=. \phi^{\prime} x \text { (anything). }
\end{aligned}
$$

${ }^{17}$ Frege i884, $\$ 78$, point 4, p. 91. 
But it seems that on this view everything and anything are denoting concepts involving all the difficulties considered in 35-39 [i.e. the problem concerning the inverted commas], on account of which we adopted the theory of 40 [the TOD]. We shall have to distinguish between "everything" and everything, i.e. we shall have: "everything" is not everything, but only one thing. Also we shall find that if we attempt to say anything about the meaning of "everything", we must do so by means of a denoting concept which denotes that meaning, and which must not contain that meaning occurring as entity, since when it occurs as entity it stands for its denotation, which is not what we want. These objections, to all appearance, are as fatal here as they were in regard to the. Thus it is better to find some other theory.

(“On Fundamentals", Papers 4: 385)

Russell realizes that the problem concerning the inverted commas is much more general than the TOD seems to suppose. It is indeed possible to eliminate by means of quantifiers and bound variables other kinds of denoting concepts as well, such as "all men", "some men", etc., but not "any man". For according to Principles, page 9I, any is intimately connected with the variable. Indeed, as seen from Frege's perspective, the variable is supposed to have no meaning on its own account. But that amounts to the same as reducing propositions about anything to singular propositions about propositional functions. However appealing such a view may be from a purely technical perspective, it is at variance with the very principle of Russell's realism, set out in \$I.2 above, and especially with the radical pluralism discussed in $\$ 3$.I.

\subsection{The discovery of crypto-Meinongianism}

In $O D$, however, Russell appears to be much more self-confident about the viability of the TOD. He decides to take the variable as fundamental and irreducible. The reduction of all kinds of ambiguously denoting phrases, save the ones beginning with the word "any", to sentences containing bound variables, is set out without any critical discussion of the former theory of denoting concepts. The main part of the text is devoted to definite descriptions. In a somewhat modified form, the "rather curious" problem concerning the explanation of the inverted commas is discussed in connection with them, mainly in order to prove that neither Russell's own former theory nor Frege's theory of sense and reference is able to adequately explain how George IV could ever have been curious about the possible identity of the author of Waverley with Scott.

Reference to Frege is also made in another part of $O D$, the second 
part, in which his view on the problem of non-being is discussed together with Meinong's theory of objects. After explaining how sentences in which definite descriptions occur may be reduced to sentences in which they do not occur, Russell introduces this second part by saying:

Why it is imperative to effect such a reduction, the subsequent discussion will endeavour to show.

The evidence for the above theory is derived from the difficulties which seem unavoidable if we regard denoting phrases as standing for genuine constituents of the propositions in whose verbal expressions they occur.

(Papers 4: 4I8)

From the use of the word "imperative" it may be inferred that Russell's attitude towards the TOD had been subjected to a considerable change. Evidently this was due to a new discovery made shortly before $O D$ was written, namely that the problem of non-being, which happened to be ignored in "On Fundamentals", puts the TOD in a much more favourable light. It reveals an unsuspected advantage of the new theory and at the same time, as its counterpart, the disadvantage of the presupposition that Meinong or the quasi-Meinongian Russell and Frege or the quasi-Fregean Russell have in common.

Which advantage does Russell have in mind? It is mentioned as such in the previous paragraph (Papers $4: 418$ ). According to the TOD a proposition expressed by a sentence of the form "the $S$ is $P$ " cannot be true unless the denoting phrase "the $S$ " actually denotes something, i.e. unless there is some entity $e$ which is such that the proposition expressed by "the $S=e$ " (which has to be construed according to the paraphrase proposed by the TOD) is true (4:423). From this it appears that the denotation is actually allowed to play some role of importance. But, and this is the distinctive feature of the TOD, this role is supposed to be limited to actual truth or falsity. The damage caused by the absence of the denotation will be limited accordingly. In the case of propositions expressed by simple sentences of the form "the $S$ is $P$ ", it merely results in their falsity, which, of course, does not prevent propositions about such relatively simple ones, i.e. propositions in whose verbal expression "the $S$ " has a secondary occurrence, from sometimes being true.

We now know what is supposed to be an advantage, but not yet why. The answer is rather obvious: there will be no truth-value gaps anymore. If we suppose, just as the quasi-Fregean Russell did, that "Zeus" is a definite description in disguise, say "the $Z$ ", and if we suppose as well, 
for the sake of argument, that all sentences in Greek mythology containing "Zeus" are of the form "the $Z$ is $P$ ", then they are all false. As far as this point is concerned, we have returned to the view of the quasiMeinongian Russell. There is, however, a significant difference. For now we are able to say that Zeus is not, without contradicting ourselves and without any need to transcend the realm of being. We simply say that for any entity $e$ the proposition expressed by "the $Z=e$ " is false. The gist of the matter is that the true proposition expressed by "Zeus is not", which indeed seems to be about something without being, is in fact a proposition about something else, namely the real falsity of an infinite number of real propositions. Neither Meinongian unreal objects, nor Fregean truth-value gaps, are involved.

As seen from the perspective of this much longed-for freedom of speech, both Meinong and Frege appear to labour under the same constraint. For trusting appearances, they both overrate the importance of the denotation in supposing that it belongs to the subject matter of the proposition. They both assume as a matter of course that a sentence such as "the smallest prime number is even" does express a proposition about the number 2. This number, they think, must be available in order to safeguard the proposition's being true or false at all. If the number were not there, the proposition's being a genuine proposition would be impossible. In this respect they regard the denoting phrase "the smallest prime number" as "standing for a genuine constituent" of the proposition. $^{\text {I8 }}$

As soon as another example is considered, say "the greatest prime number is odd", the peaceful unanimity between Meinong and Frege suddenly gets disturbed. Meinong believes it does express a true proposition about an unreal object. Frege refuses to admit unreal objects and supposes the thought expressed by this sentence to be neither true nor false.

What is the source of their controversy? It is to be found in the very presupposition they share. For the assumption that the denotation, if there is any, has to play the role of subject matter, has two mutually opposed sides, namely that if there is truth or falsity, the denotation must

${ }^{18}$ And Frege or the quasi-Fregean Russell does so in spite of their emphatic claim that the denotation is not a constituent of the proposition. As seen from the perspective of the TOD, this claim does not express anything more than a good but powerless intention. That is why it is ignored by the author of $O D$. 
be present, and if the denotation is absent, there can be neither truth nor falsity. According to the law of contraposition these two implications imply each other; they are equivalent. This equivalence seems to imply that their difference is logically irrelevant. But such a view is not acceptable, for in their actual application, they exclude each other. Of course, the two-sided principle itself cannot decide how it is to be applied in a particular case such as the above-mentioned example. But as soon as, in virtue of other considerations, a decision is made in favour of the proposition's capacity to be false or true or in favour of the complete absence of the denotation, then it actually can be applied. Meinong argues: there is truth or falsity, in this case even truth, therefore "the greatest prime number" must have a denotation. Frege, on the contrary, having rejected this conclusion, concludes that Meinong's premiss must be wrong: there is no such number; therefore there can be no truth or falsity either.

It is quite evident that, in drawing this conclusion, Frege makes use of the hypothetical principle that if there is no denotation, then there is no truth or falsity either. But as I have noted above, this principle amounts to the same as the one actually used by Meinong. This other side of Frege's presupposition will be less evident as long as it remains unused. ${ }^{19}$ That is the reason why I call it crypto-Meinongianism. In the same way, an epigone of Sartre who argues "we are free, therefore God does not exist" could be called a crypto-Calvinist.

As seen from the perspective of the TOD, crypto-Meinongianism is to be found almost everywhere, most notably in the very principle of Russell's own realism. What is more, crypto-Meinongianism in fact amounts to the same as Russell's own reflexive determinism set out in \$I.2. And it is, of course, also to be found in his quasi-Meinongianism, as appears from the first sentence of the passage quoted in \$r.3: “... Homeric gods, chimeras ... all have being, for if they were not entities of a kind, we could make no propositions about them." Therefore, the general tenor

${ }^{19}$ But in fact it is also used in Frege 1893, pp. 18-20, where an arbitrary reference is assigned to denoting phrases which in their ordinary usage would be vacuous. In this way Frege's crypto-Meinongianism becomes manifest. In order to prevent truth-value gaps from intruding into his concept-script, Frege needs an object to fulfil the supposed role of the denotation. And that is exactly what is meant in $O D$ where Russell says: "Another way of taking the same course [i.e., the one taken by Meinong] (so far as our present alternative is concerned) is adopted by Frege, who provides by definition some purely conventional denotation for those cases in which otherwise there would be none" (Papers 4: 420). 
of the official story deserves much more credit than generally supposed. By means of paraphrase the TOD purports to reveal that the real subject matter of propositions is different from their apparent one. In that way it seems to be able to leave undamaged the realm of truth and falsity without being committed to ontological extravagance.

\subsection{The official story as ideological distortion of the facts}

How much truth is contained in the official story and how much falsity? As applied to the first five points enumerated in 0.3 , this question may be answered as follows:

ad: aI Three forms of Meinongianism are to be distinguished: transrealism, which represents the outgoing and excessive character of Meinong's view, essentialism which is restrictive and realist in tenor, and finally crypto-Meinongianism which is neutral as to the distinction between real and unreal. As far as true and false propositions are supposed to be equally real, only the latter variety of Meinongianism may give rise to an "unduly populous realm of being".

ad: a2 Trans-realism is incompatible with Russell's realism, but something like it is not. Such a quasi-Meinongianism actually occurs in Principles. It is out-and-out anti-essentialist and it presupposes crypto-Meinongianism as applied to proper names.

ad: bi There is no manifest essential link between Russell's actual quasiMeinongianism and his theory of denoting concepts. The only manifest link is accidental: the theory of denoting is essential to its removal. But crypto-Meinongianism is essentially connected with both. Therefore, at least according to Russell's own later view, the quasi-Fregean attempt to avoid quasi-Meinongianism is doomed to failure.

$a d:$ b2 In fact there are two different desires involved. Neither of them is occasioned by the discovery of a difficulty in the old theory of denoting. The first, rather superficial, desire arose in 1903 and seemed to be satisfied by a Fregean use of that theory. The second, latent and deeper, desire grew stronger at the very moment Russell realized that the previously conceived TOD could satisfy it.

ad: CI Although the conception of the TOD could have been occasioned by that discovery, i.e. the discovery of crypto-Meinongianism, in 
fact it has been occasioned by a trans-Fregean attempt to avoid a problem borrowed from the orthodox Frege, the problem connected with the notion of indirect sense. And although the discovery of crypto-Meinongianism did in fact not lead to the conception of the TOD, it actually contributed to its adoption.

According to this analysis, each of these five points contains both truth and falsity. And the discrimination of truth from falsity is based on distinguishing three forms of Meinongianism and two forms of "being led" to the TOD. Not making these distinctions is what the official and the unofficial view have in common. Whether it leads to the one or the other perspective merely depends on the way these confusions are arranged. For example, if Meinongianism in general is identified with cryptoMeinongianism and "being led" to the TOD with accepting it, then the official story thus far seems to be mainly justified. If, on the other hand, Meinongianism in general is identified with essentialist trans-realism, and "being led" to the TOD with conceiving it, then the conclusion will inevitably be in favour of the established criticism.

The last two elements of the official story differ in character from the preceding ones. For it is not possible to find both truth and falsity in any of them. Point (c2), the contention that the TOD was accepted as a matter of course, is false anyhow. For initially it was rejected and afterwards the discovery of its advantage in connection with the Meinongian problem of non-being contributed to its acceptance.

One and only one question remains to be discussed, namely whether the said discovery was sufficient to give rise to Russell's full and wholehearted acceptance of the TOD. Either it was sufficient or it was not. In the first case the discovery that the eliminative approach proposed by the TOD might be helpful in solving the paradox actually took place after its full adoption; then the last element of the official story, point (c3), must be wholly true. In the latter case there is one and only one discovery that could have completed the process of adoption, namely the discovery of the link with the paradox; then point (c3) must be wholly false. The joint weight of the following four arguments is, I presume, sufficient to prove at least the plausibility of the latter alternative.

(I) The mere fact that in "On Fundamentals" the TOD is rejected cannot be denied. But its importance could be denied in arguing that Russell's initial lack of enthusiasm is only due to his not yet 
being able to cope with the revolutionary character of his brandnew theory. At that moment, it could be argued, he did not dare take the only decision required for its full acceptance: giving up all former attempts to explain the variable by means of denoting and accepting it as fundamental and irreducible. And that is exactly what is expressed in the fourth paragraph of $O D$ (Papers 4: 416).

Indeed, but the nature of both this decision and the theory which it is supposed to support remain unclear as long as the question mentioned in $\$$ 4.I (whether the variable does or does not have any meaning on its own account) is answered. For the very essence of the TOD consists in its claim that the real subject matter of a proposition in whose verbal expression a denoting phrase occurs is different from its apparent subject matter. Indeed, Russell is very emphatic in arguing that the denotation is not something the proposition is about and that in fact it plays another less important role. But he is much less emphatic about the equally essential question about what other entities actually play the role wrongly attributed to the denotation. In order to deny the variable's independent meaning, Russell has to disavow the radical pluralism implied by his realism and with it the idea of the unrestricted variable. And in order to accept that the variable does have any meaning on its own account, he has to face the following, rather nasty dilemma: either the former distinction between meaning and denotation is applied to it, or it is not. If it is, the TOD's being subordinate to the old theory of denoting concepts becomes apparent. If it is not, the TOD appears to be in flat contradiction with the principle of finite human acquaintance (see $\$_{3}$.I $)$. For in that case, a proposition expressed by a sentence containing a denoting phrase will have to consist of infinitely many constituents. And in order to understand it, we will have to be acquainted with all of them.

(2) The general tenor of $O D$ is much less unambiguous than generally supposed. This appears from its last paragraph. There Russell concludes his argument in saying:

I will only beg the reader not to make up his mind against the view [of the TOD] - as he might be tempted to do, on account of its apparently excessive complication - until he has attempted to construct a theory of his own on the subject of denotation. This attempt, I believe, will con- 
vince him that, whatever the true theory may be, it cannot have such a simplicity as one might have expected beforehand.

(Papers 4: 427)

At first sight this passage seems to be open to no other than one of the following two interpretations: either it is just the umpteenth testimony of Russell's gallantry, or it is meant to express an inevitable consequence of the fact that the argument in favour of the TOD cannot be final because the number of puzzles used as its test cases is limited. I hold, however, that another, less obvious interpretation is possible: Russell's concluding remark reflects the hidden structure of $O D$ as a whole. The main reason why underneath $O D$ 's apparent structure another is concealed is as follows. If in view of a certain puzzle it is argued that the new theory is able to solve or to avoid it and the old one is not, then such a twofold argument, provided it is valid, seems to prove that the former theory has an unambiguous advantage whose scope is limited to the puzzle in question. But - and that is the sticking point - as soon as, in the course of the critical part of the argument, in one way or other the question is raised why the old theory fails, the said principle does not hold any longer. For in that case there are two mutually opposed possibilities: either the critical argument purports to prove that the old theory fails in virtue of its deviating from the new one, or it leaves the said failure unexplained. In the first case the criticism contends to give unlimited extra support to the new theory. In the latter case, the argument, in virtue of its inability to give such extra support, casts a possibly unlimited shadow on the viability of the new theory.

This opposition is actually exemplified by the two critical arguments contained in $O D$, as appears from the use of the word "imperative" in the introduction of the discussion with Meinong and Frege (see \$4.2), and the use of the words "rather curious" in the introduction of the socalled Gray’s Elegy Argument (GEA).

(3) Just as $O D$ differs from the very first unofficial account of the TOD in containing a criticism of Meinong and Frege on the problem of non-being, so it differs from later expositions of the TOD in its containing the GEa. From Principia onwards all expositions of the TOD make use instead of another argument which purports to remove any possible doubt concerning the cause of the old theory's failure to solve the problem of informative identity: 
Thus all phrases (other than propositions) containing the word the (in the singular) are incomplete symbols: they have a meaning in use, but not in isolation. For "the author of Waverley" cannot mean the same as "Scott", or "Scott is the author of Waverley" would mean the same as "Scott is Scott", which it plainly does not; nor can "the author of Waverley" mean anything other than "Scott", or "Scott is the author of Waverley" would be false. Hence "the author of Waverley" means nothing.

$(P M \mathrm{I}: 67)$

Whatever the possible validity of this argument may be, it claims to give extra support to the TOD on account of the problem of informative identity. And it does so without taking into account the possible distinction between sense and reference or meaning and denotation, let alone the one between direct and indirect sense. Thus it can be put forward without mentioning either Frege or the Russell of Principles. And that might be a great advantage, for it implies that the critical discussion of their theories, most notably the GEA, is irrelevant to the TOD's philosophical justification. And, as I have argued in $\$ 4.2$, the same holds of the critical argument against Meinong and Frege set out in $O D$. This might explain the remarkable fact that in all expositions of the TOD from Principia onwards, Frege has disappeared from the scene; only Meinong remains.

(4) As I argued in \$o.2, any plausible account of the history of the TOD must be such that the very emergence of the distortions contained in the official story may be dealt with as an explainable historical fact. Therefore the true story must contain at least one element which can tolerate neither public daylight nor even the daylight of Russell's private consciousness. There is one and only one element that could possibly be supposed to meet this requirement, namely that the TOD was not fully accepted until the link with the paradox was discovered. For the full acknowledgement of that fact would, of course, cast a shadow on the viability of Russell's attempt to solve the paradox.

If this hypothesis is right, the connection between the TOD and the paradox is even more important than the official story suggests. And its being more important is due to the fact that the TOD and its final adoption are much more pragmatic than Russell is prepared to admit. The distortions contained in the official story are not due to its overstressing 
the importance of Meinong, for that can be justified by means of the notion of crypto-Meinongianism, but rather to its neglecting the equally important role of Frege. And this negligence springs from the attempt to ignore whatever obstructed or postponed the TOD's full acceptance. Indeed, the TOD paves the way to a fundamentally new perspective: free realism, but its justification is much more problematic than the official story suggests. ${ }^{20}$

\section{REFERENCES}

Ayer, A. J. 1971. Russell and Moore: the Analytical Heritage. London: Macmillan. Boukema, H. P. 2005. “Towards a Re-evaluation of On Denoting”. Teorema 24: I33-49.

Cartwright, R. 1987. "On the Origin of Russell's Theory of Descriptions". In his Philosophical Essays. Cambridge, Mass.: M.I.T. P. Pp. 95-I33.

Coffa, J. A. 1980. "Russell as a Platonic Dialogue". Synthese 45: 43-70.

Frege, G. I879. Begriffsschrift, ed. I. Angelelli. Darmstadt: Wissenschaftliche Buchgesellschaft, I977.

- I884. Die Grundlagen der Arithmetik, with English translation by J. L. Austin. Evanston, Illinois: Northwestern U. P., 1980.

—. I892. "Über Sinn und Bedeutung". In Kleine Schriften, ed. I. Angelelli. Hildesheim, Zürich, New York: Olms Verlag, I990. Pp. I43-62.

—. 1893. Grundgesetze der Arithmetik. Vol. I. Reprinted Hildesheim: Olms Verlag, 1966.

Griffin, N. 1996. "Denoting Concepts in the Principles of Mathematics". In R. Monk and A. Palmer, eds., Bertrand Russell and the Origin of Analytical Philosophy. Bristol: Thoemmes P. Pp. 23-64.

Hylton, P. 1990. Russell, Idealism and the Emergence of Analytic Philosophy. Oxford: Clarendon P. Pp. 237-75.

-. 2004. "The Theory of Descriptions". In N. Griffin, ed., The Cambridge Companion to Bertrand Russell. Cambridge: Cambridge U. P. Pp. 202-40.

Lackey, D. 1973. "Three Letters to Meinong: a Translation”. Russell no. 9 (spring): $15-18$.

20 The paper I presented at the "Russell versus Meinong: Ioo Years after 'On Denoting" " conference of the Bertrand Russell Research Centre, McMaster University, I4-I8 May 2005, has appeared elsewhere (see Boukema 2005). The general tenor of the present paper is essentially the same, but it approaches the subject matter in a different way: from the perspective of Russell's supposed "Meinongianism". I would like to thank Peter Simons, Gregory Landini, Russell Wahl and Gideon Makin for their comments on the first paper, and Graham Stevens for the long-lasting resistance offered in subsequent discussions about the nature and the possible reality of Russell's "Meinongianism". I also want to thank both Peter Seuren and Graham Stevens for correcting my English. 
Meinong, A. 1904. Über Gegenstandstheorie. Reprinted in Über Gegenstandstheorie, Selbstdarstellung, ed. J. M. Werle. Hamburg: Felix Meiner, I988. Pp. I5I.

Quine, W. V. O. 1948. "On What There Is". In his From a Logical Point of View. New York: Harper and Row, I96r. Pp. I-I9.

—. 1967. "Russell's Ontological Development". In R. Schoenman, ed., Bertrand Russell: Philosopher of the Century. London: Allen and Unwin.

Russell, B. 1897. An Essay on the Foundations of Geometry. London: Routledge, 1993.

—. I899. "The Classification of Relations". In Papers 2: 138-46.

-. 1900. A Critical Exposition of the Philosophy of Leibniz. London: Routledge, 1992.

-. 1903. The Principles of Mathematics. With new Introduction: London: Allen and Unwin, 1937.

_. "On Meaning and Denotation". In Papers 4: 315-58.

-. 1904. "Meinong's Theory of Complexes and Assumptions". In Papers 4: $432-74$.

-. 1905. "The Existential Import of Propositions". Mind n.s. I4: 398-40I. Papers 4: 486-9.

- "Review of Meinong et al., Untersuchungen zur Gegenstandstheorie und Psychologie". Mind n.s. I4: 530-8. Papers 4: 596-604.

_. "On Fundamentals". Papers 4: 360-4I3.

_- "On Denoting". Mind n.s. I4: 479-93. Papers 4: 4I5-27.

-. 1906. "The Monistic Theory of Truth" (secs. I-II of "On the Nature of Truth and Falsehood"). In Russell, Philosophical Essays. London: Routledge, 1994. Pp. 139-46.

-. 1909. "On the Nature of Truth and Falsehood". In Russell, Philosophical Essays. Pp. 147-59. Papers 6: 116-24.

-. I9II. "Knowledge by Acquaintance and Knowledge by Description". In Russell, Mysticism and Logic and Other Essays. London: Allen and Unwin, 1974. Pp. 152-67. Papers 6: I48-6I.

-. 1913. Theory of Knowledge. In Papers 7.

-. I9I8. "The Philosophy of Logical Atomism". In Russell, Logic and Knowledge, ed. R. C. Marsh. London: Allen and Unwin, 1956. Pp. 177-218. Papers 8: $160-244$.

—. 1919. Introduction to Mathematical Philosophy. London: Routledge, 1993.

—. 1944. "My Mental Development". In P. A. Schilpp, ed., The Philosophy of Bertrand Russell. La Salle, Illinois: Open Court, I97I. Papers II: 5-18.

-. 1959. My Philosophical Development. London: Allen and Unwin.

Whitehead, A. N., and Russell, B. I910. Principia Mathematica. Vol. I. Cambridge: Cambridge U. P. 